\title{
Magnetic resonance spectroscopy in congenital heart disease
}

Vivienne M Miall-Allen, Graham J Kemp, Bheeshma Rajagopalan, Doris J Taylor, George K Radda, Sheila G Haworth

\begin{abstract}
Objective-To determine the feasibility of studying myocardial and skeletal muscle bioenergetics using ${ }^{31} \mathbf{P}$ magnetic resonance spectroscopy (MRS) in babies and young children with congenital heart disease.
\end{abstract}

Subjects-16 control subjects aged 5 months to 24 years and 18 patients with CHD, aged 7 months to 23 years, of whom 11 had cyanotic CHD, five had cardiac failure, and two had had a Senning procedure.

Design $^{-31}$ P MRS was carried out using a 1.9 Tesla horizontal $65 \mathrm{~cm}$ bore whole body magnet to study the myocardium in 10 patients and skeletal muscle (gastrocnemius) in 14 patients, eight of whom were exercised, together with appropriate controls.

Results-In hypoxaemic patients, in skeletal muscle at rest intracellular pH $\left(\mathrm{pH}_{\mathrm{i}}\right)$ was abnormally high [7.06 (SEM $0.04) v 7.04(0.05), P<0.01]$ and showed a positive correlation with haemoglobin $(\mathbf{P}<0.03)$. On exercise, hypoxaemic patients fatigued more quickly but endexercise $\mathrm{pH}_{\mathrm{i}}$ and phosphocreatine recovery were normal, implying that an equivalent but smaller amount of work had been performed. End-exercise ADP concentration was lower. On recovery, the initial rate of phosphocreatine resynthesis was low. Skeletal muscle bioenergetics were within normal limits in those in heart failure. In the myocardium, the phosphocreatine/ATP ratio was similar in controls and hypoxaemic subjects, but low in those in heart failure.

Vascular Biology and Pharmacology Unit, Institute of Child Health, 30 Guilford Street, London WC1N 1EH

V M Miall-Allen

$S$ G Haworth

MRC Clinical and

Biochemical Magnetic

Resonance Unit, John

Radcliffe Hospital,

Headington, Oxford

OX3 9DU

G J Kemp

B Rajagopalan

D J Taylor

G K Radda

Correspondence to:

Professor S G Haworth

Professor S G Haworth,

Institute of Child Health,

30 Guilford Street,
WCIN 1EH, UK.

Accepted for publication

6 December 1995
Conclusions-In heart failure, the myocardial phosphocreatine/ATP ratio was reduced, as in adults, while resting skeletal muscle studies were normal. By contrast, hypoxaemic children had normal myocardial bioenergetics, but showed skeletal muscle alkalinity, and energy reserves were more readily depleted on exercise. On recovery, the initially slow phosphocreatine resynthesis rate reflects a low rate of mitochondrial ATP synthesis, probably due to an inadequate oxygen supply. ${ }^{31}$ P MRS offers a safe, non-invasive method of studying myocardial and skeletal muscle bioenergetics in children as young as $\mathbf{5}$ months.

(Heart 1996;75:614-619)
Keywords: magnetic resonance spectroscopy; bioenergetics of skeletal muscle; bioenergetics of myocardium; congenital heart disease

Over the past 20 years, magnetic resonance spectroscopy (MRS) has emerged as a powerful tool for the non-invasive, in vivo, investigation of the relation between energy provision and expenditure in health and disease. Initially it was performed in animals, but its application was extended to man in $1981 .^{1}$ To date, most experience with this technique in human cardiac disease has been in adults. We wished to determine the feasibility of using this technique to study infants and young children.

Poor exercise tolerance has long been recognised as a major symptom of heart failure, but has received relatively little attention until recently as it was assumed simply to reflect impaired cardiac output reserve and raised pulmonary venous pressures. It is now recognised that the degree of exercise intolerance correlates poorly with the degree of left ventricular impairment, and several groups have shown abnormalities of skeletal muscle function, metabolism, and composition in patients with heart failure-abnormalities which themselves may influence exercise capacity. ${ }^{2}$ Most of this information has come from muscle biopsies, but the technique of phosphorus-31 ( $\left.{ }^{31} \mathrm{P}\right) \mathrm{MRS}$ is now proving to be a valuable tool for the investigation of working skeletal muscle in vivo. ${ }^{3}$

In this study subjects as young as a few months of age were investigated. They had various forms of congenital heart disease and we attempted to obtain bioenergetic profiles using ${ }^{31} \mathrm{P}$ from heart and skeletal muscle whenever possible. We were particularly interested in studying those with cyanotic congenital heart disease to determine whether there was evidence of metabolic adaptation to the often profound hypoxaemia tolerated by such individuals.

\section{MAGNETIC RESONANCE SPECTROSCOPY AS A} TECHNIQUE

There are three separate but closely linked bioenergetic reactions occurring in cells, ensuring adequate provision of ATP for mechanical work in heart and skeletal muscle (fig 1): (1) oxidative phosphorylation; (2) rapid conversion of phosphocreatine (PCr) to adenosine triphosphate (ATP); and (3) anaerobic degradation of glycogen to lactic acid. The switch from aerobic to anaerobic production of ATP, for example during sustained 


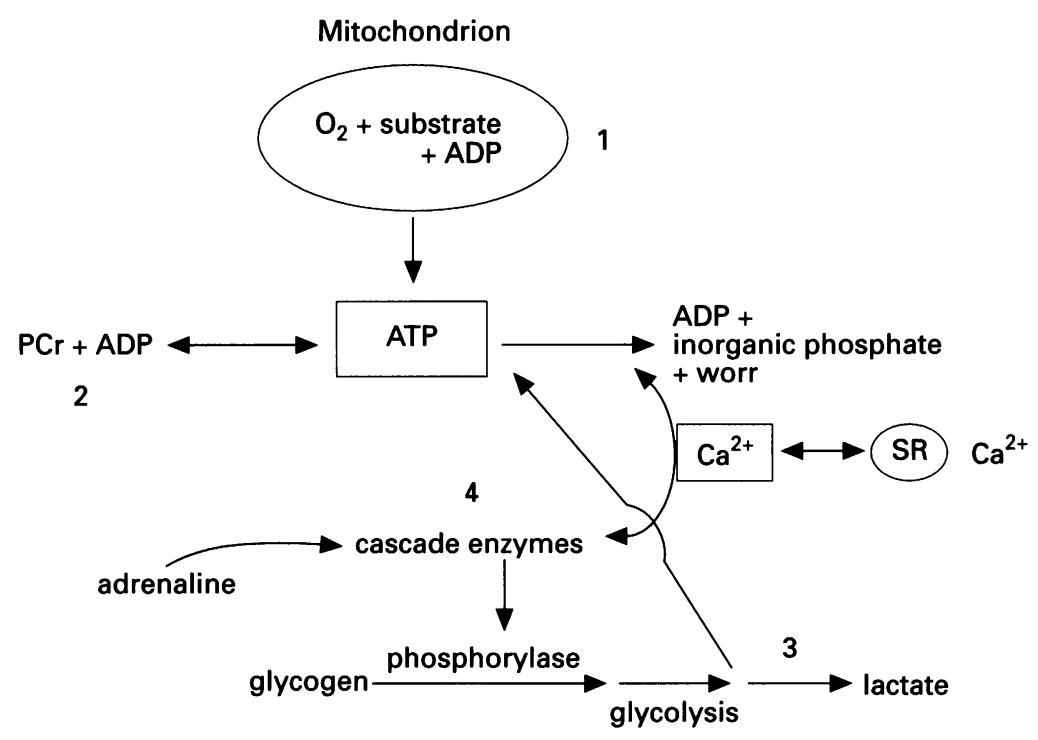

Figure 1 Bioenergetics in heart and skeletal muscle (ADP, adenosine diphosphate; PCr, phosphocreatine; ATP, adenosine triphosphate). After Radda. ${ }^{4}$

A

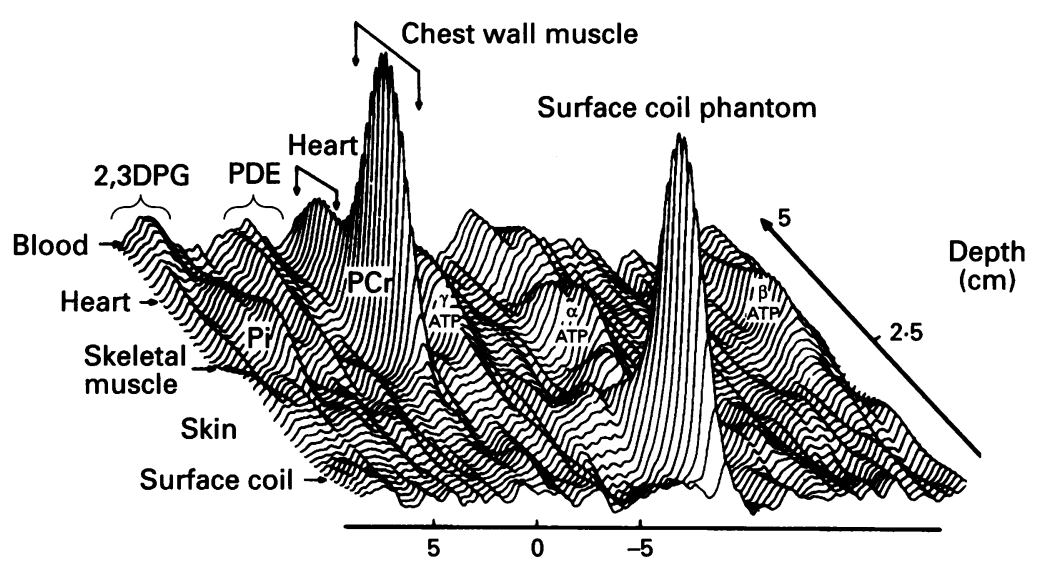

Figure 2 Examples of ${ }^{31} P$ spectra from $(A)$ normal heart, and $(B)$ skeletal muscle. (A) For the heart spectra, position on the horizontal axis from front to back corresponds to space (starting with reference phantom) and extending through the chest wall. Each row represents a slice from increasing depth. (B) ${ }^{31} P$ spectra from human gastrocnemius muscle in vivo. Data were collected using a $6 \mathrm{~cm}$ diameter surface coil with an 80 s pulse length an a 2 s interpulse delay. The 1.9 T magnet (Oxford Magnet Technology) was interfaced to a Bruker spectrometer. On the $x$ axis is the chemical shift in parts per million, and on the $y$ axis the and on the $y$ axis the
signal intensity. Peak signal intensity. Peai phosphomonoesters; (2) Pi. (3) phosphodiesters; (4) phosphocreatine (PCr); (5) y phosphate of $A T P$; (6) $-A T P+N A D H$ and NAD ; (7) $-A T P$. The spectra show muscle (a) at rest, (b) at the end of exercise, and (c) on recovery from exercise. dynamic exercise, involves a complex series of reactions catalysed by a cascade of $\mathrm{Ca}^{2+}$ dependent enzymes. ${ }^{4}$

The technique of MRS relies on the fact that phosphorus nuclei in the body become aligned with the field of a high field whole body magnet. A surface coil applied to the part of the body under investigation transmits electromagnetic energy at the resonant frequency of phosphorus and tips the nuclear spins off their previous alignment. When the applied energy is switched off, the perturbed nuclei relax back into their original alignment with the field and in so doing, release the previously absorbed energy back into the coil. After amplification, this weak electromagnetic signal can be Fourier transformed to produce a visual display of separate peaks corresponding to different metabolites (the chemical environment surrounding the phosphorus nuclei in each metabolite will slightly alter the position in the spectrum). Thus ${ }^{31} \mathrm{P}$ MRS can be used to identify and quantify high energy phosphate metabolites involved in the creatine kinase reaction.

Anatomical considerations dictate that different spectral acquisition protocols must be used to examine different structures. For example, skeletal muscle, such as gastrocnemius, has no superficial signal producing tissue to "contaminate" the spectra, so a relatively simple and rapid "pulse and collect" experiment can be performed. The heart, however, lies directly below the intercostal and transversus thoracis muscles which themselves are rich in high energy phosphates that can contaminate the spectra from the underlying myocardium. A localisation method is therefore necessary to identify uncontaminated spectra from the heart. This will be described more fully in the methods section. Examples of normal skeletal muscle and myocardial spectra are shown in fig 2.

\section{Methods}

The study protocol was approved by the Hospital's ethics committee, and informed consent for each scan was obtained. Experiments were performed with a 1.9 Tesla horizontal $65 \mathrm{~cm}$ bore whole body magnet (Oxford Technology) interfaced with a Bruker Biospec spectrometer (fig 3). We studied 16 control subjects aged 5 months to 24 years (healthy volunteers or those referred to the Hospital for Sick Children but subsequently found to have an innocent murmur or haemodynamically insignificant ventricular septal defect). Eighteen patients with congenital heart disease aged 7 months to 23 years were subdivided into the following groups: (1) cyanotic congenital heart disease (right to left intracardiac shunting), with or without previous palliative surgical intervention; (2) cardiac failure secondary to significant left to right intracardiac shunting, and (3) those who had previously undergone intra-atrial repair, a Senning procedure ${ }^{5}$ for transposition of the great arteries. The clinical characteristics and 


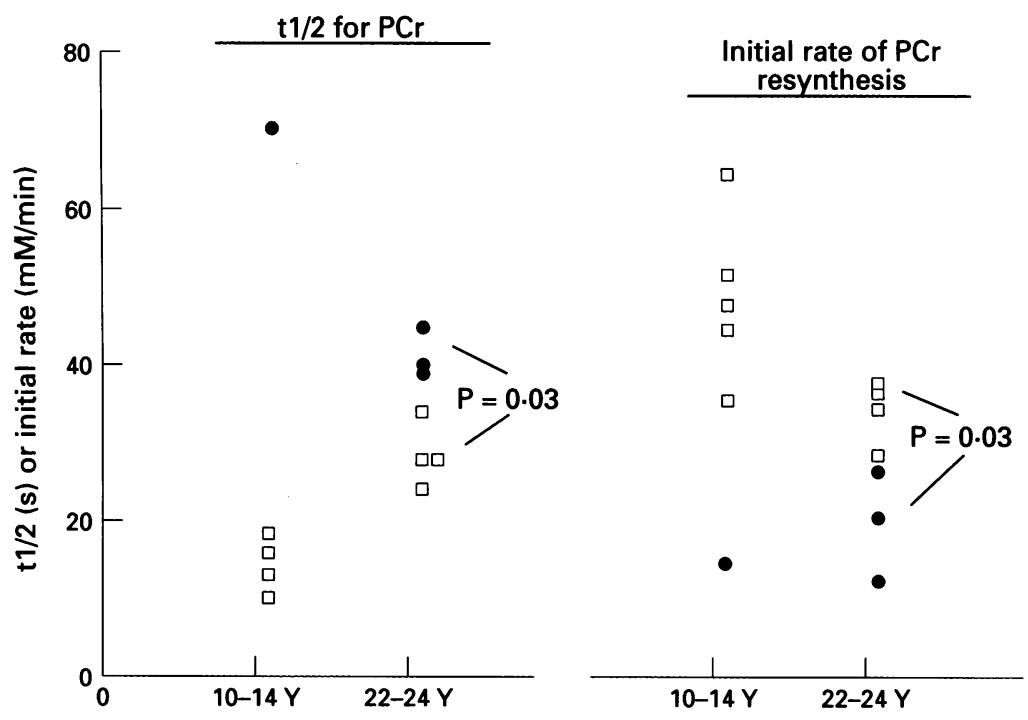

Figure $3 P C r$ recovery from exercise in hypoxaemic patients and control subjects. Data are from all of those subjects who depleted enough PCr for recovery to be measured reliably (that is, $P C r /(P C r+P i)<0.60$ at the end of exercise). Empty squares, control subjects; filled circles, hypoxaemic patients. Pi recovery was also slower in this group of patients (data not shown): $t \frac{1}{2}=45$ (3) s for patients and 22 (5) s for controls $(P=0.03)$. leys to an adjustable series of weights. The initial load was set at $10 \%$ of lean body mass (LBM) with $2 \%$ increments per minute of exercise thereafter. LBM was estimated from calliper measurements of skinfold thickness and body weight. Exercise was continued until terminated by fatigue.

\section{Recovery spectra}

During a 10 min rest after exercise, spectra were acquired as follows; four summed from eight pulses, four summed from 16 pulses, three summed from 32 pulses, and two summed from 64 pulses. This produced dynamic information about the rates of recovery to baseline values of the various metabolites.

\section{CALCULATIONS}

The peak areas of inorganic phosphate (Pi), $\mathrm{PCr}$, and ATP were determined by manual triangulation of the spectra. $\mathrm{PCr}$ is expressed as the $\mathrm{PCr} / \mathrm{ATP}$ ratio or as $\mathrm{PCr} /(\mathrm{PCr}+\mathrm{Pi})$. The latter ratio corrects for any change in signal intensity due to movement of muscle with respect to the coil during exercise.

$\mathrm{pH}_{\mathrm{i}}$ (cytosolic $\mathrm{pH}$ ) was estimated by the chemical shift on the spectrum of $\mathrm{Pi}$ relative to PCr. Adenosine diphosphate (ADP) concentration was calculated from the creatine-kinase equilibrium (assuming an equilibrium constant of $1.66 \times 10^{-9}$; cytosolic [ATP], 8.2 $\mathrm{mmol} / \mathrm{l}$ of intracellular water; total creatine, $42.5 \mathrm{mmol} / 1$ of intracellular water). Corrections were also made for partial saturation effects when deriving absolute concentrations. ${ }^{7}$

$\mathrm{PCr}$ recovery was expressed as a percentage recovery to allow for the lower $\mathrm{PCr} / \mathrm{PCr}+\mathrm{Pi}$ ratio at the end of exercise. Percentage recovery at time $t$, that is, $t \frac{1}{2} P C r$ was therefore equal to:

$$
100 \times\left(P c r_{\mathrm{t}}-P C r_{\text {end exerise }}\right) /\left(P c r_{\text {rest }}-P C r_{\text {end exercise }}\right)
$$

Recovery half-time, that is, time to $50 \%$ recovery to baseline $\mathrm{PCr}$, was obtained by graphical interpolation. Half-times of $\mathrm{Pi}$ and ADP recovery were obtained similarly.

The initial rate of $\mathrm{PCr}$ resynthesis, a direct estimate of the rate of mitochondrial ATP synthesis, was calculated from the total change in $\mathrm{PCr}$ during exercise, assuming exponential kinetics.

$$
\underset{\text { Initial rate of }}{P C r \text { resynthesis }}=\frac{\left([P C r]_{\text {rest }}-[P c r]_{\text {end exercise }}\right)}{\times 0.693}
$$

ACQUISITION OF MYOCARDIAL SPECTRA

As indicated above, a localisation method was required in order to obtain myocardial spectra that were uncontaminated by thoracic cage muscle. The method used was phase modulated rotating frame imaging. ${ }^{8}$ The positioning of the surface coil against the anterior chest wall in the prone subject was guided by preliminary cross sectional echocardiographic localisation of the right ventricle (ATL Ultramark 4, sector scanner; $3.5 \mathrm{MHz}$ scan head), with the subject lying prone on a cradle 
Table 1 Subjects studied

\begin{tabular}{|c|c|c|c|c|c|c|}
\hline \multicolumn{3}{|c|}{ (a) Control group } & \multirow[b]{2}{*}{ Diagnosis } & \multicolumn{2}{|c|}{ Gastrocnemius } & \multirow[b]{2}{*}{ Heart } \\
\hline Case & Sex & Age & & Rest & Exercise & \\
\hline 1 & $\mathbf{M}$ & $5 \mathrm{~m}$ & insignificant VSD & - & - & + \\
\hline 2 & $\mathrm{~F}$ & $10 \mathrm{~m}$ & insignificant VSD & + & - & + \\
\hline 3 & $\mathbf{M}$ & $15 \mathrm{~m}$ & insignificant VSD & - & - & + \\
\hline 4 & $\mathrm{~F}$ & $7 y$ & insignificant VSD & + & + & - \\
\hline 5 & $\mathbf{F}$ & $9 \mathrm{y}$ & healthy volunteer & + & + & + \\
\hline 6 & $\mathbf{F}$ & $10 \mathrm{y}$ & insignificant VSD & + & + & + \\
\hline 7 & $\mathbf{M}$ & $10 \mathrm{y}$ & insignificant VSD & + & + & - \\
\hline 8 & $\mathbf{M}$ & $10 \mathrm{y}$ & innocent murmur & + & + & + \\
\hline 9 & $\mathbf{F}$ & $\begin{array}{l}12 \mathrm{y} \\
\text { Mean } 6.25 \text { years }\end{array}$ & innocent murmur & + & + & + \\
\hline 10 & $\mathbf{F}$ & $18 \mathrm{y}$ & healthy volunteer & + & + & - \\
\hline 11 & $\mathbf{F}$ & $22 \mathrm{y}$ & healthy volunteer & + & + & - \\
\hline 12 & $\mathbf{M}$ & $22 \mathrm{y}$ & healthy volunteer & + & + & - \\
\hline 13 & $\mathbf{M}$ & $22 \mathrm{y}$ & healthy volunteer & + & + & - \\
\hline 14 & $\mathrm{~F}$ & $23 \mathrm{y}$ & healthy volunteer & + & + & - \\
\hline 15 & $\mathbf{F}$ & $23 \mathrm{y}$ & healthy volunteer & + & + & - \\
\hline 16 & $\mathbf{F}$ & $\begin{array}{l}24 \text { y } \\
\text { Mean } 22 \text { years }\end{array}$ & healthy volunteer & + & + & - \\
\hline \multicolumn{3}{|c|}{$\mathrm{n}=16$} & & 14 & 13 & 7 \\
\hline
\end{tabular}

\begin{tabular}{|c|c|c|c|c|c|c|c|c|}
\hline \multicolumn{5}{|c|}{ (b) Cyanotic congenital heart disease } & \multirow{2}{*}{$\begin{array}{l}0 \\
\text { sat }\end{array}$} & \multicolumn{2}{|c|}{ Gastrocnemius } & \multirow[b]{2}{*}{ Heart } \\
\hline Case & Sex & Age & Diagnosis & $(H b)$ & & Rest & Exercise & \\
\hline 1 & $M$ & $10 \mathrm{~m}$ & Taussig-Bing anomaly & $18 \cdot 0$ & $70-75$ & + & - & - \\
\hline & & & 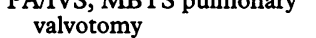 & N/D & $85-95$ & + & - & - \\
\hline $\begin{array}{l}3 \\
4\end{array}$ & $\begin{array}{l}M \\
M\end{array}$ & $\begin{array}{l}2 y \\
9 y\end{array}$ & $\begin{array}{l}\text { VSD } \\
\text { DILV/PA, hypoplastic RV, }\end{array}$ & N/D & $85-95$ & - & - & + \\
\hline & & & MBTS & $17 \cdot 8$ & $73-88$ & - & - & + \\
\hline 5 & $\mathbf{M}$ & $10 \mathrm{y}$ & DIRV/DORV, PS, Glenn & $17 \cdot 0$ & $77-93$ & + & - & - \\
\hline $\begin{array}{l}6 \\
7\end{array}$ & $\begin{array}{l}\mathrm{F} \\
\mathrm{F}\end{array}$ & $\begin{array}{l}10 \mathrm{y} \\
14 \mathrm{y}\end{array}$ & $\begin{array}{l}\text { DORV, Glenn } \\
R \text { isomerism, AVSD, PA, }\end{array}$ & 16.9 & 75-79 & + & + & + \\
\hline 8 & $\mathbf{F}$ & $19 \mathrm{y}$ & $\begin{array}{l}\text { Glenn } \\
\text { DORV + AVSD, subPS, }\end{array}$ & N/D & $75-89$ & + & + & + \\
\hline 9 & $\mathbf{M}$ & $21 \mathrm{y}$ & $\begin{array}{l}\text { no surgery } \\
\text { PA/VSD, MAPCAs, } \\
\text { corrected TGA, PS, }\end{array}$ & $\begin{array}{l}17.5 \\
17.5\end{array}$ & $\begin{array}{l}83-85 \\
82-85\end{array}$ & + & $\begin{array}{l}+ \\
+\end{array}$ & - \\
\hline 10 & $\mathrm{~F}$ & $23 \mathrm{y}$ & $\begin{array}{l}\text { hypoplastic RV } \\
\text { TV straddle, previous Glenn }\end{array}$ & $22 \cdot 9$ & 88-92 & + & + & + \\
\hline 11 & $\mathrm{~F}$ & $23 \mathrm{y}$ & $\begin{array}{l}\text { Eisenmenger PDA } \\
\text { PA/VSD, MBTS }\end{array}$ & $\begin{array}{l}15 \cdot 0 \\
17 \cdot 5\end{array}$ & $\begin{array}{l}88-89 \\
70-75\end{array}$ & $\begin{array}{l}+ \\
+\end{array}$ & $\begin{array}{l}+ \\
+\end{array}$ & $\overline{-}$ \\
\hline $\mathrm{n}=1$ & & $\begin{array}{l}\text { Mean } \\
13(8) \\
\text { years }\end{array}$ & & & & $\mathrm{n}=10$ & $\mathrm{n}=7$ & $\mathrm{n}=5$ \\
\hline
\end{tabular}

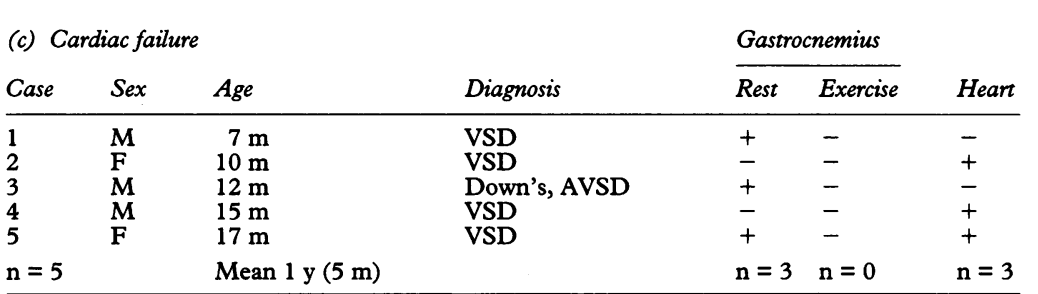

(d) Post-Senning operation

\begin{tabular}{llrlllll} 
Case & Sex & Age & & Diagnosis & Rest & Exercise & Heart \\
\hline 1 & $\mathrm{~F}$ & $8 \mathrm{y}$ & TGA, Senning, 5 m & - & - & + \\
2 & $\mathrm{M}$ & $13 \mathrm{y}$ & & TGA, Senning, 6 m & + & + & +
\end{tabular}

AVSD, atrioventricular septal defect; DILV/DIRV, double inlet L/R ventricle; DORV, double outlet right ventricle; Glenn (Shunt), surgical anastomosis between the SVC and right PA; $(\mathrm{Hb})$, haemoglobin concentration within the last 6 months; $\mathrm{g} / \mathrm{dl}$, by standard laboratory method; IVS, intact ventricular septum; MAPCAs, major aortopulmonary collateral arteries; MBTS, modified Blalock-Taussig shunt between the subclavian and branch pulmonary artery, $\mathrm{N} / \mathrm{D}$, not done; 0 , sat, oxygen saturation: range of readings during the scan by pulse-oximeter (Datex, modified for use in the magnet); PA, pulmonary artery; PS, pulmonary stenosis TGA, transposition of the great arteries; TV, tricuspid valve; VSD, ventricular septal defect.

designed to correspond with the position adopted in the magnet while lying on the surface coil. The diameter of the coil $(6,10$, or 15 $\mathrm{cm}$ ) was chosen to be appropriate for the age and size of the subject.

Spectra were obtained using a repetition rate of $3.5 \mathrm{~s}$ and acquisitions were gated to the diastolic phase of a simultaneously recorded ECG in order to remove motion artefact and collect signal during the optimal phase of the cycle. Spectra representing adjacent $0 \cdot 8-1 \mathrm{~cm}$ slices proceeding antero-posteriorly from chest wall to myocardium and then ventricular cavity were obtained. The optimal heart row was identified by a characteristically lower PCr/ATP ratio relative to overlying skeletal muscle. Whenever possible, at the end of the procedure the position of the heart relative to the coil was confirmed by proton imaging.

\section{CALCULATIONS}

The phosphocreatine to adenosine triphosphate ratio (PCr/ATP) was obtained by manual triangulation. Correction was made for ATP from any blood-contamination of the spectrum by estimating 2,3-diphosphoglycerate (2,3-DPG) from its peaks, adjacent to phosphocreatine, and assuming the ratio of DPG/ATP in blood to be 4.3 for fully saturated blood and 10 in hypoxaemia (G K Radda, unpublished observation).

\section{HAEMOGLOBIN ESTIMATION}

Seven children with cyanotic congenital heart disease had had a routine peripheral venous haemoglobin concentration $[\mathrm{Hb}]$ estimated by the hospital laboratory within two months of the MRS study. Determination of [Hb] for the sole purpose of the study in these children or in other subjects, normal or diseased, was not considered to be ethically justified.

\section{TRANSCUTANEOUS OXYGEN SATURATION}

For safety reasons, throughout the MRS data acquisition in the cyanosed group, estimates of transcutaneous oxygen saturation were made using a pulse oximeter (Datex) which had been modified for use within the strong magnetic field.

\section{STATISTICAL ANALYSIS}

Data are presented as the mean (SD). Statistical significance of differences was assessed by the Mann Whitney U test for nonparametric data.

\section{Results}

SKELETAL MUSCLE STUDIES

Resting studies

In skeletal muscle (table 2), $\mathrm{PCr} / \mathrm{Pi}$ and $\mathrm{PCr} /(\mathrm{PCr}+\mathrm{Pi})$ were similar in controls and all groups with congenital heart disease. The $\mathrm{pH}_{\mathrm{i}}$ at rest was, however, higher in the hypoxaemia group, at mean 7.06 (0.04) $v 7.04$ $(0.05)(P<0.01)$, and showed a positive correlation with $[\mathrm{Hb}](r=0.76, \mathrm{P}<0.03)$, the latter crudely reflecting the degree of chronic hypoxaemia. The mean [ADP] tended to be lower in hypoxaemic individuals compared with controls, but the difference was not statistically significant.

Skeletal muscle data were obtained in only one post Senning patient, and this showed a relatively low PCr/ATP ratio.

\section{Exercise and recovery}

During exercise, hypoxaemic patients became fatigued more quickly than controls, reflecting their generally reduced effort tolerance (table 3). However, the end of exercise $\mathrm{pH}_{i}$ and $\mathrm{PCr} /(\mathrm{PCr}+\mathrm{Pi})$ were similar in the two 
Table 2 MRS data from resting muscle. Values are means (SEM) or range (mean)

\begin{tabular}{|c|c|c|c|c|c|c|c|c|c|}
\hline Group & Age (years) & Condition & $n$ & $p H_{i}$ & Pi/ATP & $P C r / A T P$ & $P C r / P i$ & $P C r /(P C r+P i)$ & $A D P, \mu M$ \\
\hline $\begin{array}{l}A^{\star} \\
\text { B } \\
\text { C } \\
\text { D } \\
\text { E } \\
\text { F }\end{array}$ & $\begin{array}{l}0 \cdot 8-12(8 \cdot 5) \\
0 \cdot 8-14(7 \cdot 7) \\
0 \cdot 6-1 \cdot 4(1 \cdot 0) \\
13 \\
18-24(22) \\
19-23(22)\end{array}$ & $\begin{array}{l}\text { Controls } \\
\text { Hypoxaemia } \\
\text { Heart failure } \\
\text { Post-Senning } \\
\text { Cotrols } \\
\text { Hypoxaemia }\end{array}$ & $\begin{array}{l}7 \\
6 \\
3 \\
1 \\
7 \\
4\end{array}$ & $\begin{array}{l}7.04(0.05) \\
7.05(0.03) \\
7.03(0.06) \\
7.02 \\
7.01(0.02) \\
7.04(0.03)\end{array}$ & $\begin{array}{l}0.34(0.06) \\
0.39(0.05) \\
0.68(0.42) \\
0.31 \\
0.31(0.04) \\
0.31(0.04)\end{array}$ & $\begin{array}{l}2 \cdot 39(0 \cdot 12) \\
2 \cdot 55(0 \cdot 27) \\
2 \cdot 90(0 \cdot 31) \\
2 \cdot 18 \\
2 \cdot 94(0 \cdot 2) \\
2 \cdot 84(0 \cdot 18)\end{array}$ & $\begin{array}{l}7 \cdot 1(1 \cdot 2) \\
6 \cdot 5(0 \cdot 6) \\
5 \cdot 3(2 \cdot 5) \\
7 \cdot 2 \\
9 \cdot 7(1 \cdot 6) \\
9 \cdot 5(1 \cdot 8)\end{array}$ & $\begin{array}{l}0.87(0.02) \\
0.86(0.01) \\
0.82(0.08) \\
0.88 \\
0.91(0.01) \\
0.90(0.02)\end{array}$ & $\begin{array}{l}25(4) \\
21(8) \\
12(9) \\
31 \\
9(4) \\
13(4)\end{array}$ \\
\hline
\end{tabular}

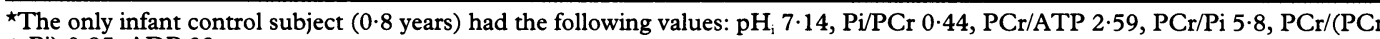
$+\mathrm{Pi}) 0 \cdot 85$, ADP $23 \mu \mathrm{m}$.

Table 3 MRS data from exercising muscle. Values are means (SEM) or range (mean)

\begin{tabular}{|c|c|c|c|c|c|c|c|}
\hline \multirow[b]{2}{*}{ Group } & \multirow[b]{2}{*}{ Age (years) } & \multirow[b]{2}{*}{ Condition } & \multirow[b]{2}{*}{$n$} & \multirow{2}{*}{$\begin{array}{l}\text { Time to } \\
\text { Fatigue (min) }\end{array}$} & \multicolumn{3}{|c|}{ End of exercise } \\
\hline & & & & & $p H_{i}$ & $P C r /(P C r+P i)$ & $A D P, \mu m$ \\
\hline $\begin{array}{l}\text { A } \\
\text { B } \\
\text { D } \\
\text { E } \\
\text { F }\end{array}$ & $\begin{array}{l}7-12(9 \cdot 8) \\
10-14(11 \cdot 7) \\
13 \\
18-24(23) \\
19-23(22)\end{array}$ & $\begin{array}{l}\text { Normal controls } \\
\text { Hypoxaemia } \\
\text { Post-Senning } \\
\text { Normal controls } \\
\text { Hypoxaemia }\end{array}$ & $\begin{array}{l}6 \\
3 \\
1 \\
4 \\
4\end{array}$ & $\begin{array}{l}13 \cdot 4(2 \cdot 2) \\
6 \cdot 7(2 \cdot 9)^{\star} \\
12 \cdot 5 \\
14 \cdot 4(0 \cdot 7) \\
10 \cdot 7(2 \cdot 1)^{\star}\end{array}$ & $\begin{array}{l}6 \cdot 84(0 \cdot 10) \\
6 \cdot 81(0 \cdot 32) \\
6 \cdot 91(0.07) \\
6 \cdot 63(0 \cdot 0) \\
6 \cdot 66(0 \cdot 23)\end{array}$ & $\begin{array}{l}0.47(0.08) \\
0.55(0.24) \\
0.61 \\
0.34(0.03) \\
0.50(0.15)\end{array}$ & $\begin{array}{l}63(4) \\
43(18) \\
53 \\
52(9) \\
31(9) \dagger\end{array}$ \\
\hline
\end{tabular}

*significantly different from control group $(\mathrm{P}=0.02$, group $\mathrm{A} v \mathrm{~B}$ and $\mathrm{E} v \mathrm{~F})$

tsignificantly different from control group $(P=0.04$, group $E v F)$

Table 4 MRS myocardial studies. Values are means (SEM)

\begin{tabular}{llll}
\hline & Age & $n$ & PCr/ATP \\
\hline Control & $6.25(5)$ years & 7 & $1 \cdot 79(0 \cdot 23)$ \\
Hypoxaemia & $8.75(8)$ years & 5 & $1 \cdot 78(0 \cdot 26)$ \\
Heart failure & $14(4)$ months & 3 & $1 \cdot 23(0 \cdot 06)^{\star}$ \\
Senning & 13 years & 2 & 1.15 \\
\hline$\star P<0.05$ & &
\end{tabular}

$\star \mathrm{P}<0.05 v$ control value

groups, implying that an equivalent amount of work had been performed, the hypoxaemic subjects reaching maximum output faster and under a smaller load. There was a significantly lower [ADP] at end-exercise in hypoxaemic individuals compared with controls.

Although there was marked individual variation in $t_{1}$ of metabolite resynthesis ( $P C r, P i$, and $\mathrm{ADP}$ ), in general this process was prolonged in the hypoxaemic individuals, although statistical significance was reached for Pi only (fig 3). The initial rate of $\mathrm{PCr}$ resynthesis was, however, significantly lower in those with cyanotic congenital heart disease.

In the child who had previously undergone a successful Senning procedure the data obtained from the exercise study were similar to control data.

MYOCARDIAL STUDIES

In the myocardium (table 4) PCr/ATP ratios were similar in controls and hypoxaemic individuals. However, the three young children with heart failure and the two who had previously undergone a Senning procedure had relatively low ratios.

\section{Discussion}

In our study, MRS was carried out on the heart and skeletal muscle in children and young adults with congenital heart disease, myocardial spectra being obtained from infants as young as 5 months of age. Magnetic resonance spectroscopy studies were well tolerated by even the youngest children. Once asleep, being positioned inside the bore of the magnet and conducting the scan did not dis- turb the babies or younger children, and the majority remained asleep for approximately one hour. This was sufficient time for collection of spectra. Older children were awake for the studies, but were generally very cooperative. In particular, they were not afraid to go into the scanner provided time was taken to explain, at a level appropriate to their understanding, what to expect. Indeed, the experience could be made positively enjoyable if they were encouraged to see the procedure as a game, and for example, pretend the scanner was a spaceship! There were no instances of claustrophobia and the required study times of up to one hour were well tolerated.

At rest, in children who generally had a low pulmonary blood flow, hypoxaemia was associated with a relative cellular alkalinity of the skeletal muscle, confirming an observation previously made by this unit. ${ }^{9}$ Tissue alkalinity has also been observed using MRS in adult patients with chronic ischaemia secondary to peripheral vascular disease. ${ }^{6}$ Apart from this difference in $\mathrm{pH}_{\mathrm{i}}$, there were no other resting bioenergetic differences between the hypoxaemic patients and either the controls or the patients in heart failure, suggesting that those with cyanotic congenital heart disease are somehow adapted to hypoxaemia at rest. Whether the increase in tissue $\mathrm{pH}$ is involved in an adaptive process is unknown, and the mechanism by which it occurs remains speculative. It is unlikely to be due to reduced production of lactic acid because metabolism at rest is oxidative. Perhaps there is an increase in the set-point of the $\mathrm{Na}^{+}-\mathrm{H}^{+}$antiporter, an exchange system important in regulation of tissue $\mathrm{pH}$.

Hypoxaemic patients were more easily fatigued on exercise. This is not surprising as it is consistent with their limited everyday effort tolerance. Although adaptive processes may be effective at rest or on minimal effort, energy reserves are more rapidly depleted with sustained effort. The end of exercise $\mathrm{pH}_{\mathrm{i}}$ values were similar in the two groups, but the rate of fall in $\mathrm{pH}_{\mathrm{i}}$ in the hypoxaemic group was greater than in controls, suggesting an increase 
in the rate of anaerobic ATP synthesis by glycogenolysis and glycolysis.

The end-exercise [ADP] was significantly lower in the hypoxaemic subjects. ADP is recognised as an important regulator of oxidative phosphorylation, and its concentration in normal muscle is inversely related to the number of mitochondria in the cells. ${ }^{10}$ The lower [ADP] in the hypoxaemic patients could be related to an adaptive increase in the density of mitochondria within the muscle in order to make maximum use of the limited amount of tissue oxygen available. In cyanotic heart disease, the slower initial rate of $\mathrm{PCr}$ resynthesis after exercise reflects a slow rate of mitochondrial ATP synthesis and is likely to be due to an inadequate oxygen supply. This explains the trend towards slow recovery half times for $\mathrm{PCr}, \mathrm{Pi}$, and $\mathrm{ADP}$ as well as the rapid $\mathrm{PCr}$ depletion in exercise.

In cardiac failure secondary to left to right intracardiac shunting, there was a reduced PCr/ATP ratio within the myocardium: $1 \cdot 23$ $(0.06)$ compared with 1.79 in the controls. This is consistent with previous findings in adults. ${ }^{11}$ Interestingly, the ratio in resting skeletal muscle was normal but we have no information on exercise because this group was too young to follow an exercise protocol. The myocardial PCr/ATP ratios were similar in controls and hypoxaemic children, but the numbers of patients studied was small and further work is indicated.

Finally, the only child we studied who had previously undergone a Senning procedure showed an abnormally low myocardial PCr/ATP ratio $(1 \cdot 15)$, suggesting bioenergetic imbalance despite an apparently good clinical result and no overt symptoms of cardiac decompensation. In such individuals the right ventricle continues to function throughout life as the systemic ventricle, and it is well recognised that there is significant risk of cardiac failure and arrhythmias some years after surgery. Further work needs to be performed to establish whether there is, consistently, a latent bioenergetic abnormality within the myocardium of the right ventricle, working against systemic loading conditions.

In conclusion, we have shown that ${ }^{31} \mathrm{P}$ MRS is possible in children of all ages. It is a safe and well tolerated technique for even the smallest child, which affords us the unique opportunity of studying bioenergetics in vivo. Its future widespread application in the clinic and research is possible.

This study was supported by the British Heart Foundation.

1 Ross BD, Radda GK, Gadian DG, Rocker G, Esiri M, Falconer-Smith J. Examination of a case of suspected McArdle's syndrome by ${ }^{31} \mathrm{P}$ nuclear magnetic resonance. $N$ Engl F Med 1981;304:1338-42.

2 Arnolda L, Conway M, Dolecki $M$, et al. Skeletal muscle metabolism in heart failure: a ${ }^{31} \mathrm{P}$ nuclear magnetic resonance spectroscopy study of leg muscle. Clin Sci 1990; 79:583-9.

3 Wilson JR, Fink L, Maris J, et al. Evaluation of energy metabolism in skeletal muscle of patients with heart failure with gated phosphorus-31 nuclear magnetic resonance. with gated phosphorus-31
Circulation 1985;71:57-62.

4 Radda GK. Potential and limitations of nuclear magnetic resonance for the cardiologist. Br Heart $\mathcal{f} 1983 ; 50$ : 197-201.

5 Jordan SC, Scott O. Cardiac lesions with common mixing. In: Heart disease in paediatrics. London: Butterworths, 1989:190-1

6 Hands LJ, Bore PJ, Galloway G, Morris PJ, Radda GK. Muscle metabolism in patients with peripheral vascular disease investigated by ${ }^{31} \mathrm{P}$ nuclear magnetic resonance spectroscopy. Clin Sci 1986;71:283-90.

7 Arnold DL, Taylor DJ, Radda GK. Investigation of human mitochondrial myopathies by phosphorus magnetic resonance spectroscopy. Ann Neurol 1985;18:189-96.

8 Blackledge MJ, Rajagopalan B, Oberhaensli RD, Bolas NM, Styles P, Radda GK. Quantitative studies of human cardiac metabolism by ${ }^{31} \mathrm{P}$ rotating-frame NMR. Proc Natl Acad Sci USA 1987;84:4283-7.

9 Adatia I, Kemp GJ, Taylor DJ, Radda GK, Rajagopalan B Haworth SG. Abnormalities in skeletal muscle metabolism in cyanotic patients with congenital heart disease: a ${ }^{31} \mathrm{P}$ nuclear magnetic resonance spectroscopy study. Clin Sci 1993;85:105-9.

10 Dudley DA, Tullson PC, Terjung RL. Influence of mitochondrial content on the sensitivity of respiratory control. f Biol Chem 1987;262:9109-14.

11 Conway MA, Allis J, Gowerbert R, Niioka T, Rajogopalan $B$, Radda GK. Detection of low phosphocreatine to ATP ratio in failing hypertrophied human myocardium by ${ }^{31 P}$ magnetic resonance spectroscopy. Lancet 1991;338: 973-6. 